\title{
DESIGN AND CONSTRUCTION OF HIGH-QUALITY CAPACITOR FOR HIGH FREQUENCY AND POWER APPLICATION
}

\author{
Martin Zav̌rel $^{1}$, Vladimír Kindl ${ }^{1, *}$, Tomáš Kavalír², Pavel Drábek ${ }^{1}$ \\ ${ }^{1}$ Regional Innovation Centre for Electrical Engineering, Faculty of Electrical Engineering, University of West Bohemia, \\ Pilsen, Czech Republic \\ ${ }^{2}$ Regional Technological Institute, Faculty of Mechanical Engineering, University of West Bohemia, Pilsen, Czech Republic \\ *E-mail of corresponding author: vkindl@kev.zcu.cz
}

\begin{abstract}
Resume
The paper proposes a design and construction of a special plated capacitor exhibiting very good high-frequency characteristics. The capacitor is designed to minimize the parasitic parameters like ESR (equivalent series resistance) and ESL (equivalent series inductance) and to be suitable for power industry applications. The paper describes the fabrication process and discusses technical issues related to technology of manufacturing and assembling. It also provides an experimental verification and the quality evaluation based on frequency characteristics compared to existing commercial high-quality capacitor.
\end{abstract}

\section{Article info}

Received 26 May 2020

Accepted 8 June 2020

Online 27 October 2020

\section{Keywords: \\ capacitor, \\ high quality, \\ high power, \\ high frequency, \\ parasitics, \\ construction design, \\ testing}

ISSN 1335-4205 (print version)

ISSN 2585-7878 (online version)

\section{Introduction}

Increasing the power density of electrical passive components, such as a capacitor [1-3], inductor or resistor, incorporated into modern power systems, is a common technical goal for many power applications. Higher power density brings better material utilization, lower weight and lower equipment cost. Many power applications are using the high frequency and sometimes the resonance, e.g. wireless power transfer [4-5], high-pass, low-pass and EMI (electromagnetic interference) filters [6-7], induction heating [8-9] etc.

In these applications, the compensation capacitors play a very important role, since they must carry very high electrical current and are being stressed with relatively high voltage. In that case, the quality factor ( $Q$ factor) of the capacitor is one of the most important characteristics in a power circuit design [10]. Besides the capacitance (the main parameter), the practical capacitor consists of equivalent series resistance (ESR), equivalent series inductance (ESL) and insulation resistance $\left(\mathrm{R}_{\mathrm{g}}\right)$ [11-13]. The electrodes and the terminals of a capacitor contribute the resistive component and the inductive component, while the dielectric material contributes the insulation resistance.

The ESR component causes energy loss in a form of heat and the ESL parameter creates a magnetic field interfering with how the current rises to the peak and falls back. The $Q$ factor then represents efficiency of a given capacitor in terms of its rate of energy loss. When neglecting influence of the insulation resistance (is too high), one may write:

$$
Q=2 \pi \frac{\frac{1 I_{m}^{2}}{2 \omega^{2} C}}{\frac{I_{m}^{2} E S R}{2 f}}=\frac{1}{\omega R C} .
$$

In Equation (1), $\omega$ represents the angular frequency of the power supply, $I_{m}$ is the magnitude of the current through the capacitor $C$ and $R$ represents its ESR. As obvious from Equation (1), the energy loss starts to dominate at higher frequencies, therefore the high $Q$ factor capacitors must be used to prevent any performance issues. This could be achieved by special design having the ultra-low ESR and so ESL. This high-quality capacitor will find its purpose in any industrial-, electronics- or medicine application [14-17] that are using frequencies even higher than tens of MHz.

This paper proposes a design of high-quality, highfrequency and high-power capacitor and describes step-bystep manufacturing and assembling process. The capacitor properties are compared to the equivalent high-quality capacitor available on the market [18].

\section{Design of the capacitor}

As mentioned in previous section, to demonstrate the quality of this design, the properties of the capacitor are compared to the existing one developed by Vishay 
Table 1 Typical properties for AD1000

\begin{tabular}{lccc}
\hline property & value & units & test method \\
\hline dielectric constant & 8.5 & -- & @10 GHz (IPC TM-650 2.5.5.5) \\
dissipation factor & 0.0023 & -- & $@ 10 \mathrm{GHz}$ (IPC TM-650 2.5.5.5) \\
temperature coefficient & $-380\left(-40 \div 150{ }^{\circ} \mathrm{C}\right)$ & $\mathrm{ppm} /{ }^{\circ} \mathrm{C}$ & $@ 10 \mathrm{GHz}$ (IPC TM-650 2.5.5.5) \\
volume resistivity & $1.4 \times 10^{9}$ & $\mathrm{M} \Omega \mathrm{cm}$ & $\mathrm{C} 96 / 35 / 90$ \\
surface resistivity & $1.8 \times 10^{9}$ & $\mathrm{M} \Omega$ & $\mathrm{C} 96 / 35 / 90$ \\
electrical strength & 24.5 & $\mathrm{kV} / \mathrm{mm}$ & $\mathrm{IPC}$ TM-650 2.5.5.5 \\
dielectric breakdown & $>45$ & $\mathrm{kV}$ & $\mathrm{IPC}$ TM-650 2.5.5.5 \\
decomposition temperature & $>500$ & ${ }^{\circ} \mathrm{C}$ & for PCB \\
temperature withstand & $60 \mathrm{~min}$ & $220{ }^{\circ} \mathrm{C}$ & $\mathrm{IPC}$ TM-650 2.4.24.1 \\
thermal conductivity & 0.81 & $\mathrm{~W} / \mathrm{m} \mathrm{K}$ & $\mathrm{ASTM} \mathrm{E} 1461$ \\
\hline
\end{tabular}

Company. Capacitor PE 140 is chosen as a benchmark. This capacitor is widely used for resonance coupling, bypassing and feeding circuits in the high power radio transmitters, high-frequency tube welding equipment, high-frequency quenching and electric stoves, high-frequency driers, etc.

The main parameters are as follows: maximum voltage $U_{\text {peak }}=16 \mathrm{kV}, \mathrm{ESR}=20 \mathrm{~m} \Omega, \mathrm{ESL}=15 \mathrm{nH}$ and $C=3 \mathrm{nF}$.

The targeted parameters of the newly designed capacitor are as follows: $U_{\text {peak }} \geq 10 \mathrm{kV}, \mathrm{ESR}<20 \mathrm{~m} \Omega, \mathrm{ESL}<$ $15 \mathrm{nH}$ and $C=10 \mathrm{nF}$.

\subsection{Electrical parameters and dimensions}

To design similar parameters that can be compared, one can use Equation (2) to determine the required main dimensions in the case if a plated topology is assumed. Here, $d$ is dielectric thickness, $S$ is active electrode surface area and $\varepsilon_{0}, \varepsilon_{r}$ represent the relative permittivity (dielectric constant) of a free space and the dielectric materiel between plates, respectively.

$$
C=\varepsilon_{0} \varepsilon_{r} \frac{s}{d}
$$

The material selected for a capacitor dielectric is high dielectric constant substrate (AD1000) that permits circuit miniaturization compared to traditional low loss materials. It is a woven ceramic fiberglass reinforced laminate for microwave printed circuit boards (PCB's). As the material shows the perfect electrical and thermal parameters (seen in Table 1), it could be used for a wide range of applications.

The overall capacitance is determined from Equation (3) assuming nearly ideal parallel interconnection of $N$ capacitor layers [19]:

$$
C_{c a p}=\varepsilon_{0} \varepsilon_{r} \frac{s}{d} N
$$

Parallel connection also has beneficial impact to the current density - Equation (4) and parasitic values minimization.

$$
J S_{k} k \geq \sqrt{\frac{\Delta T S_{k}}{R_{t h} \rho_{C u} \frac{a}{4}}} .
$$

In Equation (4), $J$ stands for the chosen current density (10 $\left.\mathrm{A} / \mathrm{mm}^{2}\right), S_{k}$ represents the usable current carrying cross-section, $\Delta T$ defines allowed warming, $R_{t h}$ represents the thermal conductivity for one layer, $\rho_{C u}$ is specific resistivity of copper, $a$ is the electrode dimension ( $a=$ $130 \mathrm{~mm})$ and $k$ represents the safety coefficient $(k=0.5)$.

The current density in Equation (4) needs to be defined regarding to the current carrying capacity (maximum current, cooling ability, etc.). The final number of layers $(N=5)$ is then defined from both the requested physical dimensions $(130 \times 130 \mathrm{~mm})$ and the overall capacitance $C_{\text {cap }} \sim 10 \mathrm{nF}$.

As a consequence, a large electrode thickness (200 $\mu \mathrm{m}$ of copper foil), usable electrode surface and five-layers connected in parallel make the current density to fulfil condition in Equation (4) up to $50 \mathrm{~A}_{\text {peak }}$.

\subsection{Mechanical and construction design}

The basic mechanical design comes out from chosen geometrical topology, i.e. number of layers, electrode dimensions, plate layer thickness, etc. As the minimization of ESR and ESL is of a great importance, the design must guarantee uniform distribution of the current density in the capacitor layers. Therefore, the physical interconnections between each layers must have the same impedance, which is moreover as small as possible. The same must be ensured within each standalone layer.

Since the AD1000 material shows relatively weak mechanical tolerance (soft and fragile), the structure of the capacitor must be supported by robust copper chassis. However, this gives the opportunity to lead the thermal loss out of the capacitor efficiently.

The basic technical drawing (Figure 1) shows the layout of the capacitor (upper) and the capacitor as a model (bottom).

The most important components, combining both the mechanical and the electrical function, are the electrical interconnections formed between individual layers. These pliable but relatively solid connections are fabricated of profiled copper sheets $(0.5 \mathrm{~mm}$ thick). The terminals on 

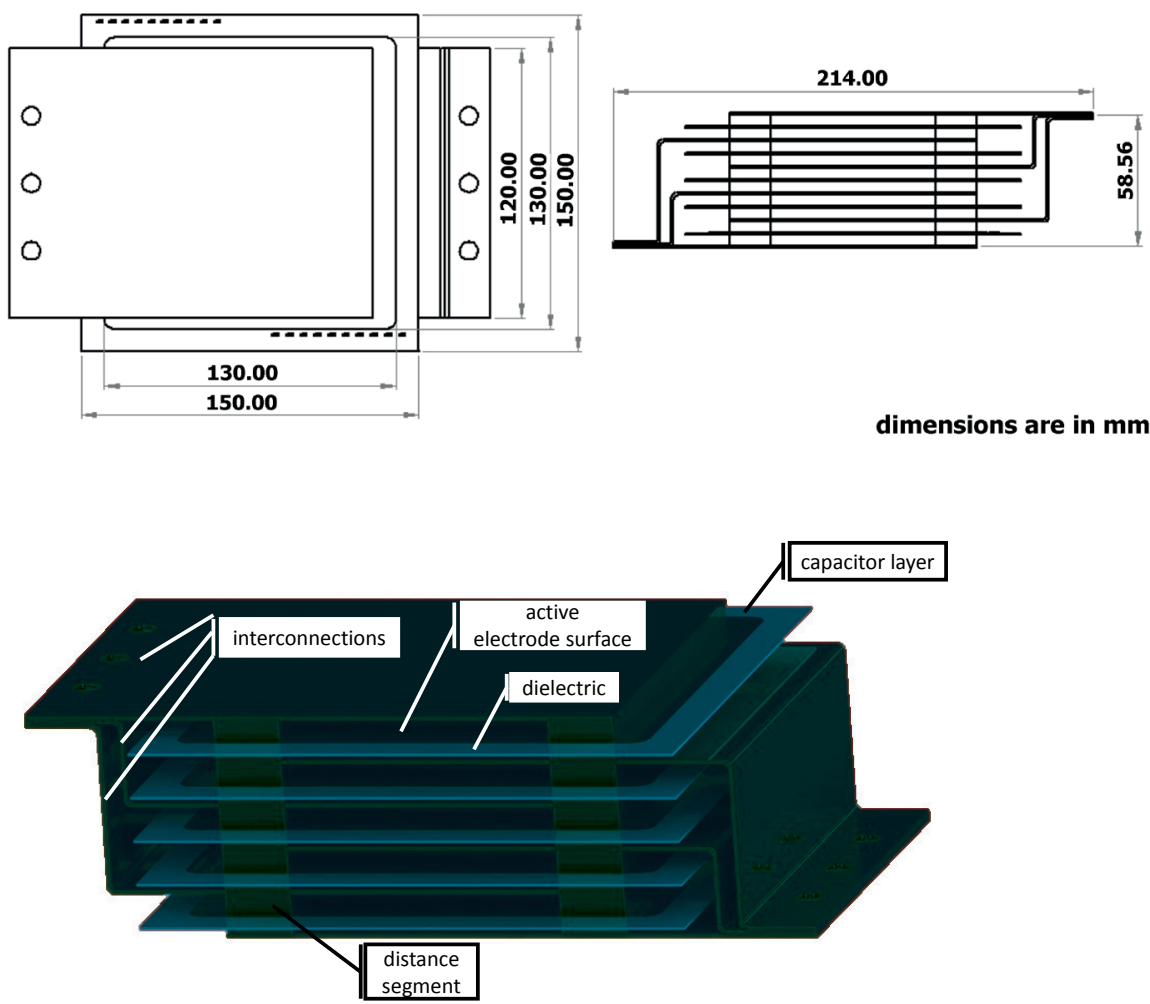

dimensions are in $\mathbf{~ m m}$

Figure 1 Basic technical layout (top), model (bottom)
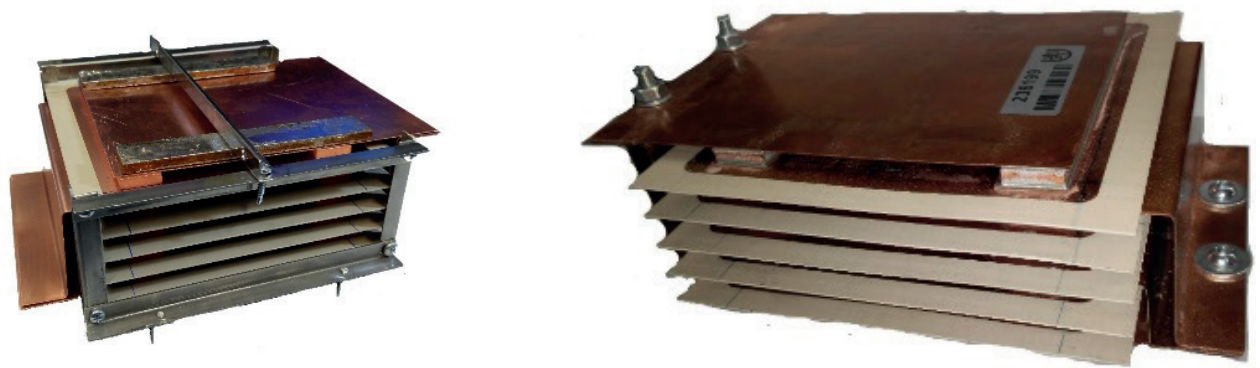

Figure 2 Capacitor prototype: in a soldering frame (left), finished (right)

both sides are made asymmetrically to compensate the different length of individual interconnection legs. The structure is further supported by a distance segments $(5 \times 18 \times 120 \mathrm{~mm})$, which are also made of copper and which significantly improve the overall mechanical stiffness. Their other advantage lies in the future possibility of improving ventilation by installing forced air cooling ducts. As seen in Figure 1, the active area of the capacitor plates are purposely reduced to form a "dielectric enlarging" that will increase the voltage breakdown and simultaneously minimize the partial discharge activity.

\section{$3 \quad$ Manufacturing process}

\subsection{Soldering and surface finishing}

The interconnections between all the construction parts are made using soft soldering. During the soldering process the paste S6M-XM3S has shown perfect temperature behavior while reaching satisfactory low reflow temperature $\left(182{ }^{\circ} \mathrm{C}\right)$ and good electrical properties of resulting interconnections. The solder paste was applied onto each contact surface in a very thin layer. The capacitor structure was stacked into the supporting frame (Figure 2 - left) to avoid layers to move during the soldering process (reflow).

The key issue is to find a proper heating source for the soldering process that will protect the surface from any damage. Direct resistance heating is not feasible due to the geometry issues. Indirect resistive heating (heating hotplate) is inappropriate because of really low thermal conductivity of dielectric material. Induction heating is possible, but it requires special equipment, which makes the technology very expensive for the prototype.

The high temperature air-flow heating cannot be used since it will irreversibly damage the surface, which was observed when manufacturing the first prototype. The best 

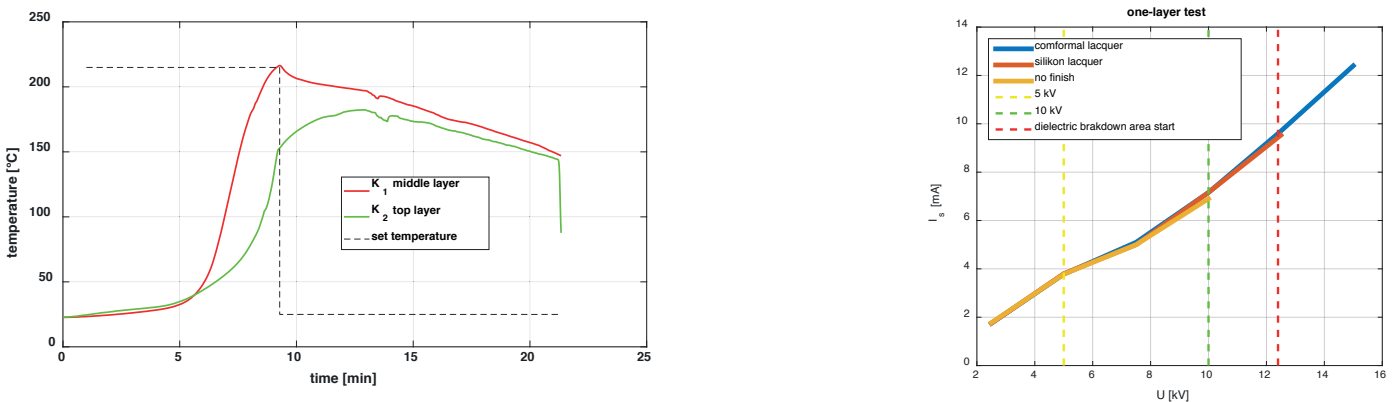

Figure 3 Heating proces in Galden vapor; temperatures (color lines) measured with a high quality sensors (PT100) located in the center of the distance elements, required temperature (black dashed lines). Breakdown tests of one layer of the capacitor after the surface finishing (right)
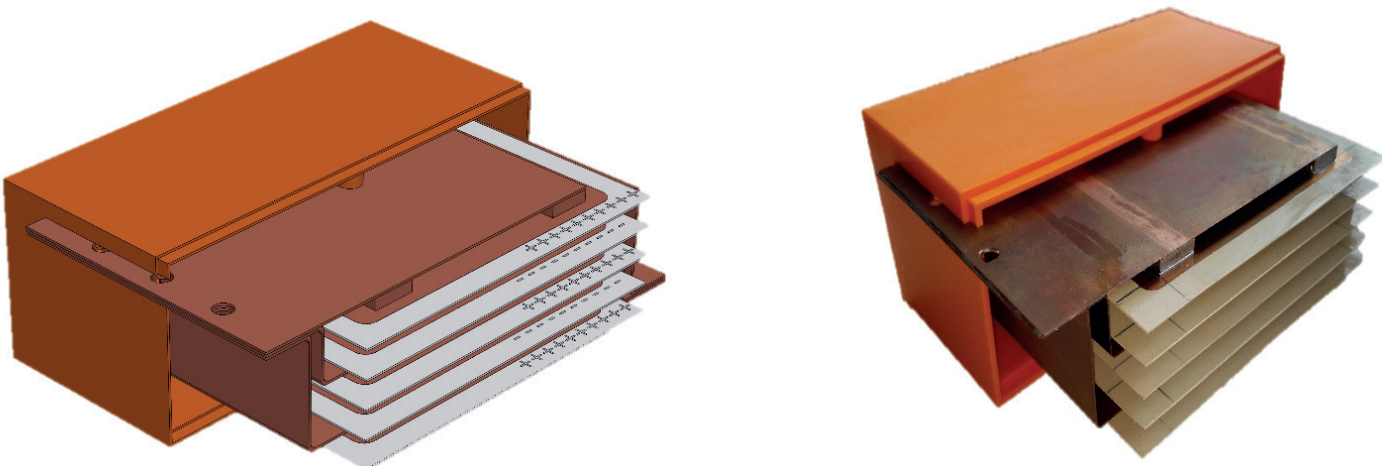

Figure 4 Capacitor in one half of housing, 3D model (left) and photo (right)
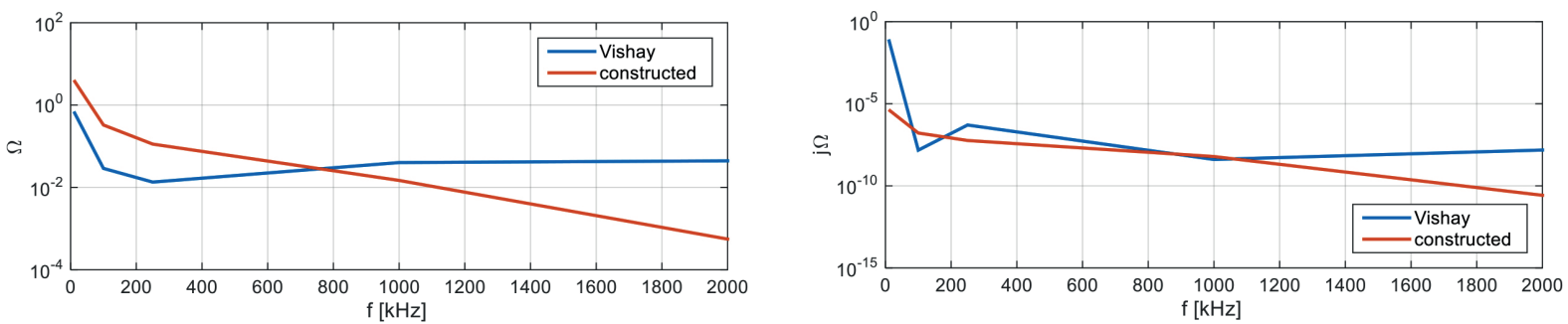

Figure 5 Measured ESR (left) and ESL (right)

Table 2 Measured capacitor parameters

\begin{tabular}{|c|c|c|c|c|}
\hline parameter & symbol & frequency & value & units \\
\hline & & $100 \mathrm{kHz}$ & 12 & $\mathrm{kV}$ \\
\hline \multirow[t]{3}{*}{ maximum repeatable $\mathrm{AC}$ voltage } & $\mathrm{U}_{\text {peak }}$ & $1 \mathrm{MHz}$ & 12 & $\mathrm{kV}$ \\
\hline & & $2 \mathrm{MHz}$ & 12 & $\mathrm{kV}$ \\
\hline & & $100 \mathrm{kHz}$ & 10.45 & $\mathrm{nF}$ \\
\hline \multirow[t]{3}{*}{ nominal capacitance } & $\mathrm{C}_{\mathrm{n}}$ & $1 \mathrm{MHz}$ & 11 & $\mathrm{nF}$ \\
\hline & & $2 \mathrm{MHz}$ & 14 & $\mathrm{nF}$ \\
\hline & & $100 \mathrm{kHz}$ & 112 & $\mathrm{~m} \Omega$ \\
\hline \multirow[t]{3}{*}{ equivalent series resistance } & ESR & $1 \mathrm{MHz}$ & 14 & $\mathrm{~m} \Omega$ \\
\hline & & $2 \mathrm{MHz}$ & 0.556 & $\mathrm{~m} \Omega$ \\
\hline & & $100 \mathrm{kHz}$ & 57.9 & $\mathrm{nH}$ \\
\hline \multirow[t]{3}{*}{ equivalent series inductance } & ESL & $1 \mathrm{MHz}$ & 6.1 & $\mathrm{nH}$ \\
\hline & & $2 \mathrm{MHz}$ & 0.0266 & $\mathrm{nH}$ \\
\hline & & $100 \mathrm{kHz}$ & 50 & A \\
\hline \multirow[t]{2}{*}{ nominal current (RMS value) } & $I_{n}$ & $1 \mathrm{MHz}$ & 50 & A \\
\hline & & $2 \mathrm{MHz}$ & 50 & A \\
\hline
\end{tabular}


results were finally reached using the Galden vapor heating seen in Figure 3 (left side).

The capacitor voltage breakdown is not directly given by a dielectric materials and thickness, but it is also influenced by the surface partial discharges. Application of the surface dielectric coating (silicon lacquer HCS Electrolube) will keep the partial discharge activity at the minimal level (Figure 3) and will protect the surface from moisture and pollution. The surface finishing was applied by soaking, dripping and curing after the soldering process.

\subsection{Housing}

The housing is the final step of the design and manufacturing process and is important due to protection against an electric shock. The housing is composed of the two components ( $4 \mathrm{~mm}$ thick wall) fabricated by a 3D printer using ABS material having sufficiently high electrical strength [20]. The capacitor placed in one half of housing is shown in Figure 4.

\section{Experimental verification}

The prototype has been tested in a wide frequency range (from 10 to $2000 \mathrm{kHz}$ ) using a precise laboratory RLCmeter (Keysight E4980A). The frequency characteristics of the constructed capacitor are compared to characteristics of existing commercial high-quality capacitor (Vishay PE 140).

Both the ESR and ESL in terms of frequency are shown in Figure 5. As obvious, the constructed capacitor shows better results starting the higher tested frequencies (> $750 \mathrm{kHz}$ for ESR and > $200 \mathrm{kHz}$ for ESL). This could be improved/adjusted by choosing another substrate for the capacitor plates. The material that was used is predicted mainly for very high frequencies. Compared to that, Vishay PE 140 ( $3 \mathrm{nF}$ and more) is designed for frequencies up to $100 \mathrm{kHz}$ only.

Measured parameters of the manufactures capacitor under different tested frequencies are given in Table 2. The data correspond to the graphs in Fig. 5.

\section{Conclusions}

Since the high-voltage high-frequency and high-quality capacitors are very expensive and usually not accessible on the market, a capacitor of the new design has been developed. The capacitor is constructed using the soft soldering and the geometry design allowing to increase the voltage breakdown and to minimize the partial discharge activity.

The capacitor housing works as the protection against the electric shock and forms a supporting mold for possible resin casting. As shown in Figure 5, the designed capacitor exhibits better performance compared to the Vishay capacitor starting at a frequency of $800 \mathrm{kHz}$ and higher.

The parameters reached during the laboratory measurement are listed in Table 2.

The manufactured capacitor has also been successfully tested as a compensation capacitor for the $5 \mathrm{~kW}$ wireless power charger [21].

\section{Acknowledgment}

This research has been supported by the Ministry of Education, Youth and Sports of the Czech Republic under the RICE - New Technologies and Concepts for Smart Industrial Systems, project No. LO1607 and by funding program of the University of West Bohemia number SGS2018-009.

\section{References}

[1] BANDALO, F. S., SINGH, B., SEVIGNY, R. Audible noise and high-voltage power capacitors. IEEE Transactions on Power Delivery [online]. 2018, 33(5), p. 2437-2441. ISSN 0885-8977. Available from: https://doi.org/10.1109/ TPWRD.2017.2774506

[2] SARJEANT, W. J., ZIRNHELD, J., MACDOUGALL, F. W. Capacitors. IEEE Transactions on Plasma Science [online]. 1998, 26(5), p. 1368-1392. ISSN 0093-3813. Available from: https://doi.org/10.1109/27.736020

[3] BRAY, K. R., KOSAI, H., SCHWEICKART, D. L., RAY, B. High temperature capacitor performance. in a high power, high frequency converter. In: IEEE International Power Modulator and High Voltage Conference IPMHVC 2012: proceedings [online]. 2012. p. 276-279. Available from: https://doi.org/10.1109/IPMHVC.2012.6518733

[4] KINDL, V., FRIVALDSKY, M., SPANIK, P., PIRI, M., JAROS, V. Transfer properties of various compensation techniques for wireless power transfer system including parasitic effects. COMPEL - The International Journal for Computation and Mathematics in Electrical and Electronic Engineering [online]. 2017, 36, p. 1198-1219. ISSN 0332-1649. Available from: https://doi.org/10.1108/COMPEL-04-2016-0143

[5] COVIC, G. A., BOYS, J. T. Modern trends in inductive power transfer for transportation applications. IEEE Journal of Emerging and Selected Topics in Power Electronics [online]. 2013, 1(5), p. 28-41. ISSN 2168-6777, eISSN 2168-6785. Available from: https://doi.org/10.1109/JESTPE.2013.2264473

[6] WANG, R., BOROYEVICH, D., BLANCHETTE, H. F., MATTAVELLI, P. High power density EMI filter design with consideration of self-parasitic. In: 27th Annual IEEE Applied Power Electronics Conference and Exposition APEC 2012: proceedings [online]. 2012. ISSN 1048-2334, p. 2285-2289. Available from: https://doi.org/10.1109/APEC.2012.6166141 
[7] WANG, X., RAVI, L., ALBERT, M. P., TALLAM, R. M. A novel configuration of DC link EMI filter capacitors in variable frequency drives. In: IEEE Applied Power Electronics Conference and Exposition APEC 2019: proceedings [online]. 2019. p. 2603-2607. Available from: https://doi.org/10.1109/APEC.2019.8721782

[8] PHADUNGTHIN, R., HAEMA, J. Application study on induction heating using half bridge LLC resonant inverter. In: 12th IEEE Conference on Industrial Electronics and Applications ICIEA 2017: proceedings [online]. 2017. eISSN 21582297, p. 1582-1585. Available from: https://doi.org/10.1109/ICIEA.2017.8283090

[9] CLARK, F. M., SCOVILLE, M. E. Capacitors for high-frequency induction-heating circuits. Transactions of the American Institute of Electrical Engineers. 1945, 64(11), p. 791-796. ISSN 0096-3860, eISSN 2330-9431.

[10] BARTLEY, P. G., BEGLEY, S. B. Quality factor determination of resonant structures. In: IEEE Instrumentation and Measurement Technology Conference: proceedings [online] 2006. ISSN 1091-5281, p. 312-316. Available from: https://doi.org/10.1109/IMTC.2006.328435

[11] ZHANG, H., JIANG, Q. Accurate measurement of key parameters of film capacitors for EV power control unit. In: IEEE 4th International Future Energy Electronics Conference IFEEC 2019: proceedings [online]. 2019. p. 1-5. Available from: https://doi.org/10.1109/IFEEC47410.2019.9014981

[12] MOONMIRAT, P., HOMKLINTIAN, M., KUMTAWEE, C. Measurement of the frequency dependence of standard capacitors in the frequency range $10 \mathrm{kHz}$ to $1 \mathrm{MHz}$. In: Conference on Precision Electromagnetic Measurements CPEM 2016: proceedings [online]. 2016. eISSN 2160-0171, p. 1-2. Available from: https://doi.org/10.1109/CPEM.2016.7540688

[13] WON, S. Y., JOO, J. H., KIM, H. S., HWANG, D. S., LEE, K. J. Performance analysis of single film electrode of the L-C resonance capacitors for using high-frequency induction heating processing equipment. In: IEEE International Telecommunications Energy Conference INTELEC 2015: proceedings. 2015. p. 1-5.

[14] IEEE standard, test code, and recommended practice for induction and dielectric heating equipment. In: IEEE Std No 54-1955 [online]. IEEE, 1955. eISBN 978-1-5044-0389-4, p. 1-24, Available from: https://doi.org/10.1109/ IEEESTD.1955.7430213

[15] AL BASTAMI, A., JURKOV, A., GOULD, P., HSING, M., SCHMIDT, M., HA, J. I., PERREAULT, D. J. Dynamic matching system for radio-frequency plasma generation. IEEE Transactions on Power Electronics. 2018, 33(3), p. 1940-1951.

[16] HSIEH, M., KUO, L., WU, E., CHEN, J. Imaging adult zebrafish brain structures using micro-fabricated RF coil on 3T MRI system. In: Joint Meeting of the 6th International Symposium on Noninvasive Functional Source Imaging of the Brain and Heart and the International Conference on Functional Biomedical Imaging: proceedings. 2007. p. 98-100.

[17] IHNAT, P., RUDINSKA, L., ZONCA, P. Radiofrequency energy in surgery: state of the art. Surgery today [online]. 2013, 44, p. 985-991. ISSN 0941-1291, eISSN 1436-2813. Available from: https://doi.org/10.1007/s00595-013-0630-5

[18] P. 70, P. 100, P. 140, P. 200 RF power plate capacitor with contoured rim - Vishay company [online]. Product datasheet. 2019. Available from: https://www.vishay.com/docs/22082/p70p100p140p200.pdf

[19] Capacitors and dielectric - Lumen Learning [online]. 2020. Available from: https://courses.lumenlearning.com/austinccphysics2/chapter/19-5-capacitors-and-dielectrics

[20] HOFF, B. W., MAESTAS, S. S., HAYDEN, S. C., HARRIGAN, D. J., GRUDT, R. O., OSTRAAT, M. L., HORWATH, J. C., LEONTSEV, S. Data on dielectric strength heterogeneity associated with printing orientation in additively manufactured polymer materials. Data in Brief [online]. 2018, 20, p. 480-489. ISSN 2352-3409. Available from: https://doi.org/10.1016/j.dib.2018.07.070

[21] KINDL, V., ZAVREL, M., DRABEK, P., KAVALIR, T. High efficiency and power tracking method for wireless charging system based on phase-shift control. Energies [online]. 2018, 11(8), p. 1-19. eISSN 1996-1073. Available from: https://doi.org/10.3390/en11082065 